\title{
Patrick Née, Ailleurs et poésie (Mallarmé) - L'Ailleurs maritime chez Rimbaud
}

\section{Nicola Ferrari}

\section{Q OpenEdition \\ 1 Journals}

\section{Edizione digitale}

URL: http://journals.openedition.org/studifrancesi/9008

DOI: $10.4000 /$ studifrancesi.9008

ISSN: 2421-5856

\section{Editore}

Rosenberg \& Sellier

\section{Edizione cartacea}

Data di pubblicazione: 1 octobre 2008

Paginazione: 484-485

ISSN: 0039-2944

\section{Notizia bibliografica digitale}

Nicola Ferrari, «Patrick Née, Ailleurs et poésie (Mallarmé) - L'Ailleurs maritime chez Rimbaud», Studi

Francesi [Online], 155 (LII | II) | 2008, online dal 30 novembre 2015, consultato il 08 janvier 2021. URL: http://journals.openedition.org/studifrancesi/9008 ; DOI: https://doi.org/10.4000/studifrancesi.9008

Questo documento è stato generato automaticamente il 8 janvier 2021.

\section{(c) (i) (9)}

Studi Francesi è distribuita con Licenza Creative Commons Attribuzione - Non commerciale - Non opere derivate 4.0 Internazionale. 


\title{
Patrick Née, Ailleurs et poésie (Mallarmé) - L'Ailleurs maritime chez Rimbaud
}

\author{
Nicola Ferrari
}

\section{NOTIZIA}

Patrick Née, Ailleurs et poésie (Mallarmé), in «Romantisme», n. 137, 3-2007, pp. 125-135.

Patrick Née, L'Ailleurs maritime chez Rimbaud, in «Littérature», n. 147, septembre 2007, pp. 3-20.

1 Sebbene pubblicati su differenti riviste, i due articoli dedicati da Patrick Née all'osservazione delle rifrazioni, nell'opera di Rimbaud e Mallarmé, del concetto di Ailleurs costituiscono un polittico da leggere unitariamente, sia per l'ovvia interdipendenza dei contenuti, sia per un impianto analitico e un respiro formale condivisi. Comune ai saggi, infatti, risulta la tripartizione che, dal significativo regesto delle immagini tematiche nell'opera degli autori trattati, giunge alla loro interpretazione in chiave metapsichica, attraverso la ricostruzione delle freudiane 'scene primitive' dei soggetti poetanti.

2 Il riconoscimento della pervasività della relazione tra l'Ici e l'Ailleurs nella scrittura di Rimbaud ne limita l'analisi alle ricorrenti immagini marine (sia come effettiva presenza di luoghi, dalla terrasse al promontorio, nei quali le acque e il cielo cerchino una reciproca fusione, sia nell'insistenza sui due tipi di imbarcazione - 'canot immobile' e 'arche' - emblemi contraddittori delle possibili navigazione verso l'Alterità, sia infine nell'uso metaforico per rappresentare linguisticamente gli effetti dell'assunzione di sostanze allucinogene). Per Mallarmé invece, la declinazione tematica si costruisce in un corpo a corpo con l'eredità romantica e, soprattutto, baudelairiana. Oggetto di indefinito tentennamento, in un movimento continuo di attrazione/repulsione, tra rinuncia e persistenza, tra scoperta del crollo del soprasensibile (sul quale fondare 
metafisicamente il valore poetico) e credenza in una risalita verso l'Ailleurs originale (che, ritrovato, permetta al soggetto di reintegrare la sua parte divina), l'interpretazione metafisica dell'Ailleurs si definirebbe primariamente per Mallarmé come esperienza all'interno del linguaggio.

3 La suggestiva ricchezza delle analisi testuali tende però a irrigidirsi nella griglia ermeneutica della loro interpretazione psicanalitica. La collocazione dell'immaginario dell'Ailleurs all'interno delle similmente contraddittorie scene psichiche di Rimbaud (nel conflitto tra desiderio di fuga e pulsione di morte, tra movimento e immobilità, tra l'istanza fusionale dell'Ici e dell' Ailleurs, femminile e materna, e la regressione extrapoetica nel mondo del colonialismo mercantile) e Mallarmé (che alla volontà dissolutiva nel flusso vitale, privilegia un'esigenza di compensazione) tende a ridurre la multiforme ricchezza - e interazione storica, creativa, culturale e strutturale dell'immaginario simbolico, all'astratta fissità di una uniforme (e prevedibile) tassonomia di sintomi. 